multiple-eyed catheter, some of whose eyes are resting in the prostatic urethra, is then washed through with an ounce of sterile water, and evidence noted of any pink stain indicating the passage of the dye from the vasostomy, and thereby an unobstructed lumen above the epididymis. In the event of such a combination of eventualities, i.e. active sperms in an epididymal cyst and a free lumen above, the vas should be sectioned obliquely close to the epididymis and an anastomosis effected between the cyst and the vas-vaso-epidymostomy-using the very finest suture materials. Where epididymal cysts are not present, attempted anastomosis must be made between the obliquely sectioned vas and the epididymal tubules. Occasionally a stricture may be found in the vas amenable to excision and subsequent end-to-end anastomosis. ' It is the experience of most British urologists (Kidd, Swan, I925) who have undertaken this work that successes are very infrequent, but nevertheless the procedure should not be condemned out of court as several American workers have reported successes, notably McKenna (I9I9), Hagner (I93I).

In conclusion, we must reiterate that in all cases of childless marriage of two years and upwards, a full investigation of the male partner should be made, and where proven deficiency exists, modern therapeutic methods offer at least some hope of success.

\title{
BIBLIOGRAPHY
}

1. CHARNY, J., Amer. Journ. Med. Sc., April 1944.

3. KIDD, SWAN et alii, Proc. Royal Soc. Med. (Sect. Urol.), 18, 56, I925.

4. McKENNA, C. M., Surg. Clinics, Chicago, 3, I45, rgrg.

5. RUBINSTEIN, H. S., Journ. Amer. Med. Assn., Nov. 1938; Southern Med Jour., May 1939

6. SMITH, R. E.,, Guy's Hosp. Repts., Oct. r937.

-7. SOIFER, S., Úrol. and Cutan. Rev., 45, I37, I941.

\section{A NOTE ON THE PROBLEM OF SUBFERTILITY}

\author{
By C. S. LANE-ROBERTS, C.V.O., M.S., F.R.C.O.G. \\ (Gyn. Surg., Royal Northern Hosp., London, etc.)
}

A recent leading article in The Times pointed out that in the I850's there were $18,000,000$ people in England, of whom 2,250,000 were women capable of bearing children, whereas in the I940's there were 4I,000,000 people, of whom just under 10,000,000 were capable of bearing children. Yet in the ten years I933-42 these ten millions have produced 390,000 fewer babies in England and Wales than the $2 \frac{1}{4}$ millions produced in the ten years $I 85 \mathrm{I}-\mathrm{I} 860$.

Thus the existing generation of potential parents, though of record size, will at this present rate grow into a generation of old age pensioners. It is the ageing of our population, with all that it implies in economic policy and in imperial and international affairs, that is a far more serious issue than the total size of our population.

At the other extreme is the condition of India and of its population problem. Professor Blacklock concludes in a recent paper: "If the world achieves lasting peace, if the maximum productive use of land is practised, and if, moreover, there is a sustained effort to apply our knowledge to the betterment of the health of man by attention to the prevention of disease and to improving housing, environment and nutrition, then India, with all these newly-acquired aids towards increase in the numbers and the good health of families, will be so rapidly populated that starvation will inevitably result, and that soon!"

Thus in the British Commonwealth differing methods will be called for in order to deal scientifically with under population on the one hand and over population on the other.

D. V. Glass and C. P. Blacker conclude their Population and Fertility (I938) with the following trenchant sentences: "When we see the causes of declining fertility in their full complexity and discern their manifold groupings and combinations we recognise how enormous is the task of putting really effective counter-measures into operation. Problems of the most imposing character will confront the reformer and the legislator. When we survey the picture of social life in England to-day we are impressed with the number and the excellence of the reasons why married couples should have few children. Again the spread of planned parenthood may 
well result in a further decline in fertility unless the social conditions of the future promise to fulfil better than heretofore the high standards which parents are increasingly demanding for their children. ... .

"Indeed it is possible that the desire to raise fertility may soon become one of the most potent forces making for social progress; and if, at some time in the future, the peoples of the world collectively object to raising children for cannon fodder, if they respond to national policies likely to lead to war by refusing to have children, this desire may even become a force making for international peace."

\section{British Social Hygiene Council}

After a conference had been convened by the British Social Hygiene Council a summary was published which reflects the views formed by British and American investigators.

This first emphasised the numbers of involuntary sterile marriages: then stated that from investigations among groups of industrial workers, and of middle-class families, permanent childlessness is rarely deliberate. In about 90 per cent of childless couples, who had been married for at least five years, the absence of children was caused by low fecundity. Among similar groups it was found that the small family (two children) is also often due to low fecundity, and that fecundity tends to fall after the first or second confinement and after miscarriages.

Low reproductive power in men is also common, in fact it would appear from the examination of many thousands of cases that average male fecundity is much lower than is commonly assumed - at least one out of every five men examined-and these mostly in good general health.

Of the industrial groups the bulk had accepted their fate without seeking specific help from any doctor or clinic, but in less than 5 per cent was adequate or even relevant advice given. Middle-class women ask for guidance much more frequently. In the great majority of cases examination and advice still tends to be limited to the wife, while recognition of the common. male responsibility is relatively rare.

As there are close on one million barren marriages (as far as can be estimated) in Great Britain, the seriousness of the position is obvious.

\section{Family Planning Association}

Few people yet realise how often a childless marriage is involuntarily so. Indeed, each year a steadily increasing proportion of women presenting themselves at gynaecological clinics of hospitals throughout the country complain of the failure to conceive. What help and advice have we as yet to offer these sub-fertile couples? Usually treatment is desultory and haphazard, whereas there is a crying need for it to be established on a sound scientific basis in multiple centres throughout the length and breadth of the land. The numbers of specialising subfertility clinics actually in operation can be counted on the fingers of the hand, and they are of necessity very scattered, so that the major part of the country is entirely out of reach of any facilities for even the most elementary investigation. When the somewhat alarming present population trends come to be realised, as indeed they are just beginning to be now, there will be a flood of propaganda let loose, but most of it in vain, as things are at present. Indeed, there will be great disquiet because the sub-fertile who are already asking for much and receiving very little, will soon be asking for a great deal more.

It is in order to help these subfecund couples that the Family Planning Association earlier this year circularised its branches throughout the country in the hope that their clinics--about fifty in number-might see their way to run an occasional session called the Motherhood Clinic.

It is felt that many non-fertile women would not of themselves seek advice at a hospital on such a personal and intimate matter, but would do so through the medium of the regular clinic patients.

If such a scheme proves a workable one, it is hoped that the closest co-operation may be maintained between the subfertile couple and the clinic doctor, who should, when possible, interview both husband and wife. More and more is it coming to be realised that the majority of sterile matings turn out after investigation to be due to some degree of subfertility in both partners, and that the wife should not be investigated without the husband.

A great number of subfertile marriages respond to quite elementary advice so that many investigators are of opinion that, though the ultra-specialised clinics are urgently needed, it is well worth while developing existing clinics, such as those of the F.P.A. 
It is always hoped that the centre doctor will keep in touch with the patient's general practitioner, as this is of the utmost importance from the start to the finish of the investigation. Indeed, the study of many cases of childlessness has become a very complicated investigation so that many general practitioners probably would be glad to let their patients avail themselves of these Motherhood Clinics.

It will be a long time before expert help will be available to all-nor is there much likelihood that the average country patient who seeks advice in this matter can obtain expert help.

The F.P.A. has long been in touch with working-alass family life through the medium of its contraceptive centres, scattered throughout the British Isles. These clinics, it is felt, can reach a certain type of patient who is not likely to present herself at a hospital outpatient department, complaining of sterility.

Dr. Margaret Jackson, who is contributing to this series of articles, has for some time conducted an F.P.A. centre in a South-West country town. Here she has lately developed a Sub-fertility Clinic, where her work has reached an exceptionally high standard. In fact the management of this clinic, the degree of co-operation with the local hospital, the university, etc., the skilful handling of the patients, the prosecution of active research, the thoroughness of the treatment available, and, last but not least, the most excellent results that are obtained, all combine to furnish a very fine example to all of us.

Several provincial university and other centres are beginning to launch out into sterility clinics of the ultra-specialised types. These, it must be realised, demand the services of an expert gynaecologist, andrologist, biochemist, pathologist, radiologist, and psychiatrist, all working together.

In the approach to the investigation of each sub-fertile couple the true spirit of scientific enquiry should always be kept before the investigator, for only thus, and by pooling all available data, can progress really be made. No sketchy treatment should be tolerated; case sheets should be kept, careful notes taken, and then, and only then, shall all benefit by each other's consistent thoroughness. It is not hundreds of cases that are needed, it is hundreds of thousands, with the ensuing crystallisation of the true scientific conclusions.

\section{General Survey.}

Absolute sterility has been defined by Meaker as "a state in which the initiation of the reproductive process is, at any rate for the time being, definitely impossible," and states that "it may be temporary or permanent, and that relative fertility and relative sterility are the degrees of conceptive capacity intermediate between absolute fertility and absolute sterility"

The words subfecundity and subfertility are at present interchangeably used.

A simple classification is:-

\section{Primary sterility or primary subfecundity.}

It is thought that about 20 per cent of all cases of impaired reproductive capacity in men and women fall in this group. On the male side, among constitutional disorders, pituitary deficiency, and among local condiditions, orchitis, are important. On the female side constitutional disorders, which may result in hypoplasia of the genital organs or the occurrence of anovulatory cyclès, are causal factors.

\section{Secondary sterility or secondary subfecundity.}

One child sterility falls in this group and is often brought about by slight lesions even after a normal confinement, but frequently there has been a complicated delivery or miscarriage.

Decrease in fertility is common among men and women, to a certain extent being physiological, but the degree varies from case to case and may in extreme conditions be very marked.

\section{Dyskyesis.}

The incapacity to carry pregnancy to term, shows itself in the recurrent abortion case without any trauma or disease being detectable.

Not only do endocrine dysfunctions and local disease in the female genital tract cause this condition, but, more recently, it has been found due to deficient chorionic development, the result in its turn of subnormal semen. 
Meaker in I934 laid down the following as the requisites of absolute fertility, or physiological perfection of the mechanism of conception, with the corresponding dysfunction in each group:-

(i) the testicles must produce normal spermatozoa-deficient spermatogenesis;

(ii) the male genital tract must allow for the free passage of spermatozoa from the testicle to the urinary meatus-obstruction and occlusion in male genital tract;

(iii) the prostato-vesicular secretions must be favourable to spermatozoa-hostility of prostato-vesicular secretions;

(iv) ejaculated spermatozoa must be safely delivered to and received by the cervixfaults of delivery and reception;

(v) the endocervical secretions must be favourable to spermatozoa-hostility of endocervical secretions;

(vi) the uterus must allow the free passage of spermatozoa from the cervix to the ostia uterina of the tubes-uterine blockade;

(vii) the tubes must allow the tree ascent of spermatozoa and descent of ova-tubal obstruction and occlusion;

(viii) the ovario-tubal hiatuses must allow the free passage of ova from the ovaries to the ostia abdominalia of the tubes-impassability of ovario-tubal hiatuses;

(ix) the ovaries must produce normal ova-deficient oogenesis.

Although a good deal of advance has been made since that date on the methods of approach in subfertile cases, the above makes a clear-cut programme, and one easy to follow, step by step.

The enquiry into the existing subfertility factors in a subfertile couple is not always a lengthy affair. Frequently some minor gynaecological condition calls for advice and suitable adjustment. If the problem, however, is a more complex one, then it is usual to carry out a far more exhaustive investigation, depending on the facilities available at that particular clinic. The co-ordination and interpretation of the results of these examinations usually locates one or more subfertility factors among the following groups:

i. Pelvic pathological lesions, either inflammatory or neoplastic.

ii. The cervical factor, the nature of the cervical plug of mucus and the reception of the inseminated spermatozoa.

iii. The tubal factor, whether of lack of function, of occlusion, or of spasm.

iv. The endocrine factor on the female side, with its varying effects on the reproductive function.

v. The male factor in its many ramifications.

Only quite a small percentage turn out to be due to absolute sterility of either husband or wife. Indeed, in Meakers' very extensive experience multiple etiological factors were found to be present in over 60 per cent of his cases of primary and secondary sterility.

It is therefore essential that both husband and wife should submit to a thorough investigation if any degree of success is to be attained.

\section{The Importance of Diagnosis}

The importance of accurate diagnosis is manifest, but to ensure this more data are necessary, more clinics are urgently needed. Only thus can thousands of cases be investigated, evidence be sifted, differing views correlated, and so, from frequent publications of results, the best methods of treatment be established in each individual case.

The subject of seminology, to mention only one branch, is truly in its infancy. Had it not been for hostilities and the inevitable four-year stoppage of all research work, opinions would by now have become much more stabilised.

However, it is fortunate that in the Animal Research Stations great progress has been made, despite the war, and at one in particular, under the inspiration and guidance of Professor Hammond and Dr. Walton, much excellent work has been and is being done. Doubtless co-operation in the animal field will do much to elucidate the many problems of human seminology.

It is enough to mention a dozen other compartments of the subfecundity question, in all of which research work is urgently needed. 
(i) The bearing of the minor endocrinopathies on subfertility.

(ii) The occurrence, the timing, the most suitable tests for ovulation, and the question of how often are cycles anovulatory.

(iii) Suitable treatment for women with recurrent anovular cycles.

(iv) The hypoplastic uterus and its reactivity to ovarian hormones.

(v) The Fallopian tubes, their function, their changes through the menstrual cycle, the elucidation and the bearing on diagnosis and subsequent treatment of patency, with or without proper function, non-patency, tubal spasm, tubal stenosis, and tubal function in its bearing on subfertility.

(vi) The suitability of certain cases for the kymograph tracing, of others for the opaque oil hysterosalpingogram.

(vii) The importance of hormone analysis, the most complicated procedure of all.

(viii) The survival and fertilisability of the ovum after ovulation, also the survival of the spermatozoon in the genital tract.

(ix) The bearing of the cervical plug of mucus on the passage of the sperm, its alteration through the cycle, the influence on it of cervicitis and the so-called cervical erosion. Indeed there is a great deal to be learnt about the physiology and pathology of the cervical canal and of the increasing importance of the Sims post-coital test in the assay of both male and female subfecundity.

(x) The tendency to miscarriage, or the dyskietic factor, and the associated influence of male subfertility.

(xi) The chorionic gonadotropic hormone concentration test and its influence on the tendency to miscarriage.

(xii) The part played by the vitamins in the maintenance of reproduction, such as that of vitamin $\mathrm{E}$ in cases of recurrent miscarriage, etc.

\section{Conclusions}

This introductory and somewhat superficial survey has set out to try and show the importance of the subfecundity problem, stressing in particular the following points:-

I. The progressive ageing of our population and the crying need, as Sir Leonard Hill has pointed out, of "Britain needs four in every family;"

2. The surprisingly high percentage rate of involuntary sterile marriages.

3. The urgency for the establishment of subfertility clinics throughout the country so that suitable advice and treatment, even if of a somewhat elementary standard, can be made available to far greater numbers.

4. As soon as such clinics have been established and, of course, also as many full-scale expert sterility centres as possible, a suitable propaganda campaign should be inaugurated, the Government deciding how best maternity can be both encouraged and honoured and made practicable.

5. With the resulting increase in applications for help and advice everything should be done to encourage research, to collect data, to improve diagnosis, and to stabilise and make available to all the best and most suitable treatment. 